\title{
COVID-19: IMPACTOS ECONÔMICOS NO SETOR VAREJISTA DE MATERIAIS DE CONSTRUÇÃO NA CIDADE DE GUARAPUAVA- PR
}

\author{
Anderson Demetrio (CENTRO UNIVERSITÁRIO CAMPO REAL) (adm- \\ andersondemetrio@camporeal.edu.br). \\ Henrique Gomes Ramos (CENTRO UNIVERSITÁRIO CAMPO REAL) (adm- \\ henriqueramos@camporeal.edu.br). \\ Maxwell Raul Pellizari (CENTRO UNIVERSITÁRIO CAMPO REAL) (adm- \\ maxwellpellizari@camporeal.edu.br) \\ Fernando Volanin da Silva (CENTRO UNIVERSITÁRIO CAMPO REAL) \\ (prof_fernandovolanin@camporeal.edu.br) \\ Mônica Antoniucci Lima Motta (CENTRO UNIVERSITÁRIO CAMPO REAL) \\ prof_monicamotta@camporeal.edu.br)
}

\section{Resumo}

Objetivo: O presente artigo tem por objetivo demonstrar algumas estratégias que as empresas do setor varejistas (de materiais de construção) vêm adotando mediante a situação de instabilidade econômica gerada pela pandemia do novo coronavírus (COVID - 19) e como os consumidores estão reagindo diante desse novo cenário de mudanças emergenciais. Método: O artigo se delimita a demonstrar alguns dados quantitativos e qualitativos coletados através de pesquisa na cidade de Guarapuava, situada no estado do Paraná. Tal pesquisa tem por objetivo demonstrar os impactos e as estratégias adotadas pelas empresas do setor varejista de materiais de construção mediante a pandemia causada pelo vírus COVID - 19. Ao aplicar um questionário com perguntas objetivas e discursivas, obteve se dados gráficos e ideias de como as empresas de materiais de construção de Guarapuava - PR estão reagindo à pandemia. Resultados: Verificou-se que $76 \%$ das empresas estão se adequando ao delivery e utilizando aplicativos como Whatsapp ${ }^{\circledR}$, Facebook ${ }^{\circledR}$ e Instagram ${ }^{\circledR}$ para atendimento aos clientes. No período de aplicação da pesquisa observa-se também que houve uma diminuição de $48 \%$ em relação às vendas neste período de instabilidade. Conclusão: Diante de um cenário econômico instável conclui-se que as empresas buscam se adequar às normas, decretos e principalmente se reinventar neste período de grandes desafios causados pela pandemia gerada pelo novo Coronavírus em diversos setores da economia em especial no setor varejista de materiais de construção.

Palavras-Chaves: COVID-19. Instabilidade. Estratégias. 


\section{Introdução}

Atualmente o Brasil foi surpreendido com uma pandemia de escala global. Na visão de Ujvari (2011), pandemia é uma epidemia que atinge grandes proporções, como a "gripe espanhola", que causou a morte de cerca de 20 milhões de pessoas em todo o mundo, entre os anos de 1918 a 1919.

O Ministério da Saúde define a COVID-19 como “[...] uma doença causada pelo coronavírus SARS-CoV-2, que apresenta um quadro clínico que varia de infecções assintomáticas a quadros respiratórios graves.” A pandemia vem gerando um caos na saúde dos brasileiros e consequentemente vem trazendo inúmeros impactos em diferentes setores da economia brasileira.

Várias empresas de diferentes setores já sentem os impactos ocasionados pela COVID-19. Como é o caso do setor varejista de materiais de construção, por exemplo, o qual vem buscando alternativas para adaptar-se ao novo cenário de instabilidade.

O presente artigo delimita-se a demonstrar alguns dados quantitativos e qualitativos coletados através de pesquisa na cidade de Guarapuava, situada no estado do Paraná. Tal pesquisa visa demonstrar os impactos e as estratégias adotadas pelas empresas de materiais de construção mediante ao cenário já mencionado.

O tema abordado justifica-se pela contextualização entre o cenário supracitado que o setor varejista de materiais de construção de Guarapuava- PR vem enfrentando nos últimos meses do primeiro semestre do ano de 2020. Os apontamentos, opiniões e dados numéricos obtidos através da pesquisa reforçam as ideias do tema escolhido.

\section{O cenário}

Mediante a situação de pandemia gerada pelo novo Coronavírus ou COVID-19, as empresas são afetadas em todas as áreas e a área funcional de marketing exerce um papel fundamental, como instrumento norteador das decisões que a empresa irá tomar com base na análise de quatro principais elementos. O mix de marketing ou 4P's são denominados por Kotler e 
Keller (2012) como produto, preço, promoção e praça, os quais são responsáveis pela fundamentação do marketing de uma organização.

Para Las Casas (2011. p. 255), o produto deve ser como "objeto principal da comercialização. Ele é desenvolvido para satisfazer o desejo ou necessidade de determinado grupo de pensadores". Quando a empresa agrega valor ao produto, tende a ter uma aceitação mais perceptível perante o cliente.

O preço determina a geração de receita de serviços ou produtos. Segundo LAS CASAS (2011), o preço representa a relação de troca com os clientes. É por meio desse composto do marketing que é gerado a receita, sendo os demais considerados custos pelo autor.

É através da praça que os produtos chegam até os clientes. Dessa forma, escolher o ponto de distribuição, visando disponibilizar produtos e serviços de com toda conveniência possível e estar o mais próximo de seus fornecedores se faz de suma importância ao setor de materiais de construção especialmente em situações de instabilidade. Como aponta Las Casa (2011, p. 295) "O que caracteriza esse tipo de distribuição é o que os fornecedores devem estar presentes nos mercados que desejam atuar".

A promoção para Kotler e Keller (2015, p. 180) "Dizem respeito a incentivos e recompensas para induzir os clientes a comprar algo agora em vez de depois". Em suma, o mix de marketing se faz um instrumento norteador para as empresas de diferentes setores em situações adversas e caóticas como o novo cenário que a pandemia causada pelo novo coronavírus trouxe.

Kotler e Keller (2012, p.4) evidenciam que "marketing é um processo social pelo qual indivíduos e grupos obtêm o que necessitam e desejam por meio da criação, da oferta e da livre troca de produtos de valor entre si”. Ao analisar essa definição observa-se o marketing como processo de troca entre necessidades de determinados indivíduos em um contexto específico por um bem ou serviço ofertado visando suprir necessidades emergentes.

Com as organizações cada vez mais competitivas cabe a elas buscar meios para fidelizar seus clientes fazendo com que sempre haja a volta de consumidores após suas compras tornando se um relacionamento entre clientes e empresas na visão de Falcão (2019).

Segundo Kotler e Keller (2012), clientes procuram produtos que lhes tragam um retorno esperado tudo isso acompanhado de um preço e qualidade adequada e acertar na forma de distribuição e promoção para atingir o resultado esperado daquele produto. 
Para Polizei (2010), deve se oferecer muito mais do que apenas preço para seus clientes um simples desconto e até mesmo um prazo de pagamento pode fazer com que seus clientes após a compra observem outras vantagens na empresa. Cada vez mais os clientes estão exigentes na hora da compra cabe às organizações se adequar com essas normas buscando atender a satisfação e trazendo de alguma forma benefícios para esses clientes (KOTLER e ARMSTRONG, 2003). De acordo com Polizei (2010, p. 35), "este levantamento de cada concorrente permite que se possa distinguir a oferta da concorrência e apresentar algo de maior valor aos olhos do consumidor".

Dentro do mix de Marketing, os "Ps" de promoção e praça são fundamentais para o momento atual do país, onde dentro dos mesmos onde está a resolução de como a empresa continuar em andamento, por meio de suas divulgações de produtos, também pelos canais de distribuição dos mesmos, pois o cliente não pode sair de casa.

Mediante a esse cenário empresas buscam estratégias para sobreviver e também para manter suas conexões com seus clientes que estão em isolamento em seus lares sendo assim a inteligência de mercado é de extrema importância para as empresas, pois auxilia a administrar melhor as tomadas de decisão de acordo com o que acontece no mercado.

Com os decretos de isolamento social várias empresas deixaram de atender em suas lojas físicas e estão buscando alternativas para se manter no mercado, não se sabe até quando essa crise se estenderá, no entanto os impactos negativos já estão sendo sentidos por vários empresários, muitos já fecharam suas portas e outros buscam alternativas para se manter, analisando o comportamento de seus consumidores optando por serviço delivery e vendas pela internet.

\section{Análise do ambiente}

Analisar o ambiente onde se está situado significa um importante passo dentro da administração estratégica, se realizada com uma determinada frequência permite evidenciar as principais origens de riscos, ameaças e possíveis oportunidades inerentes à empresa.

Dar atenção às mudanças que ocorrem no ambiente seja ele micro ou macro, se torna uma forma de buscar constante aperfeiçoamento para empresa. Do contrário, ignorar os fatores ambientais pode resultar no surgimento de problemas irreversíveis em um cenário de instabilidade. 
Segundo Fernandes e Berton (2005) o macroambiente, correspondem a fatores que a empresa dificilmente pode alterar. Fatores externos correspondem a questões políticas, econômicas e sociais que influenciam diretamente a empresa, porém não é possível modifica-las.

O ambiente político-legal compreende as agências de normas, especificações e leis. Kotler e Keller (2012) descrevem que é formado por leis, órgãos governamentais e grupos de pressão que exercem influência, e ainda, que muitas vezes as leis criam oportunidades de novos negócios. É notória a influência impactante que o ambiente já mencionado exerce sobre as empresas. Criando oportunidades ou ameaças as quais podem atrapalhar o bom andamento da mesma no mercado.

No município de Guarapuava-Pr, foram adotados decretos baseados nos decretos estaduais como pode ser analisado no trecho do DECRETO no 7823, de 23 de março de 2020: "O PREFEITO DO MUNICÍPIO DE GUARAPUAVA, Estado do Paraná, no uso das atribuições que lhe são conferidas por Lei, considerando o Decreto $n^{\circ} 7815 / 2020, n^{\circ} 7820 / 2020, n^{\circ}$ 7821/2020 e n 7822/2020;" o qual considera no artigo primeiro do inciso XIII, setor varejista de materiais de construção e afins como serviço essencial para população local.

Em 24 de abril de 2020, foi sancionado o decreto de n $^{\circ} 7904$ em Guarapuava-Pr, o qual determina novos horários de funcionamento ao comércio em geral do município e limitações quanto ao número de pessoas em circulação no interior dos estabelecimentos.

Ambiente sociocultural refere se como sendo conjunto de práticas, costumes, tradições, ética e moral convencionada na sociedade. "A partir de nosso ambiente sociocultural, observamos, quase inconscientemente, a visão de mundo que define nossa relação conosco, com outras pessoas, organizações, a sociedade a natureza e o universo" (Kotler e Keller, 2012 p.81).

Tais fatores mencionados pelos referidos autores, apresenta de maneira sucinta aspectos os quais influenciam nas decisões de consumo dos indivíduos em relação ao ambiente nos quais foram criados e condicionados ao logo dos anos. As organizações devem estudar com atenção o ambiente sociocultural que desejam atingir com seus produtos ou serviços em diferentes contextos.

No âmbito econômico existe uma ligação direta com aspectos influentes da receita dos consumidores tais como inflação, taxa de juros, alteração cambial, Produto Interno Bruto (PIB), entre outros. Kotler e Keller (2012, p. 80) argumentam que "o poder de compra em 
uma economia depende da renda, dos preços, da poupança, do endividamento e da disponibilidade de crédito". E ainda, que as tendências que afetam o poder de compra gerado pela crise economia, refletem diretamente nos negócios.

A instabilidade econômica gerada pelo advento da pandemia do COVID-19 tem reflexos diretamente no poder de compra dos consumidores do setor varejista de materiais de construção de Guarapuava - Pr.

Segundo Kotler e Keller (2012) às tecnologias emergentes estimulam os índices de crescimento da economia em contrapartida os ritmos acelerados das inovações tecnológicas podem estagnar a economia. "Quando os setores estabelecidos combatem ou ignoram as novas tecnologias, seus negócios entram em declínio”. (Kotler e Keller, 2012 p. 83).

O maior desafio em questão da instituição é entender as inovações, os novos meios de gerenciamento a partir de sistemas, de oferecer produtos e serviços em um cenário mercadológico transitório e instável. O uso de aplicativos como Whatsapp ${ }^{\circledR}$, Facebook ${ }^{\circledR}$ e Instagram ${ }^{\circledR}$ se intensificou, como uma alternativa para atendimento ao cliente, desde o início da pandemia, conforme dados obtidos através de pesquisa de campo pelos autores.

Em linhas gerais o ambiente demográfico estuda a população humana no que se refere a sua extensão, idade, gênero, raça, densidade e sua ocupação e outros dados estatísticos conforme Kotler e Keller (2012).

O chamado "ambientalismo corporativo" se depara com uma eminente necessidade de estar a par de questões ambientais para elaborar planejamento tático das empresas. Devem compreender as ameaças e oportunidades ligadas a quatro vertentes do meio natural como: "a escassez de matérias-primas, especialmente de água, o custo mais elevado de energia, os níveis mais altos de poluição e as mudanças no papel dos governos" (Kotler e Keller, 2004 p $83)$.

Segundo Certo e Peter (2010), o microambiente, ou ambiente interno é composto por fornecedores, clientes, prestadores de serviços e política da empresa. Define-se cliente como os indivíduos que adquirem produtos e serviços que a empresa oferece.

Em suma toda a estrutura empresarial se fundamenta em atender as necessidades de seus potenciais clientes. Enquanto o fornecedor tem por finalidade oferecer aportes para empresa 
desenvolver produtos e serviços para o mercado que atende. "Confiabilidade de entrega, preço e reputação do fornecedor são extremamente importantes para os produtos habitualmente pedidos." (Kotler e Keller 2004 p. 212). Ao selecionar os fornecedores deve atentar seu grau de confiabilidade e sua flexibilidade nas negociações periódicas dos subsídios que a empresa necessita.

Quando ocorre uma disputa pelos mesmos clientes entre empresas pode se dizer que ocorre uma relação de concorrência. Kotler e Keller (2004) definem: "A concorrência abrange todas as ofertas e os subsídios rivais, reais e potenciais que um comprador possa considerar". (Kotler e Keller 2004 p.10).

Para tanto, a análise do microambiente e do macroambiente empresarial levam às empresas a buscarem uma estratégia efetiva para a garantia de uma vantagem competitiva e que tenham rentabilidade em especial mediante os cenários de instabilidade econômica e as mudanças recorrentes da pandemia gerada pelo novo coronavírus.

\section{Metodologia}

Segundo Gil (2008), metodologia é o caminho a ser percorrido que se utiliza métodos científicos que são fundamentais para obtenção de metas e objetivos e que de alguma forma gere resultados e conhecimentos.

Pesquisa é um conjunto de ações que tem como propósito resolver algum tipo de problema de "está empenhada na elaboração de diagnósticos, identificação de problemas e busca de soluções. Respondem a uma demanda formulada por "clientes", atores sociais ou instituições”. (Thiollent, 2009, p.36).

Para obter dados mais detalhados sobre o cenário em que setor varejista de materiais de construção de Guarapuava - PR foi utilizada pesquisa quantitativa e qualitativa para obter resultados sobre o impacto do COVID-19 nas organizações tanto em quesitos numéricos e também sobre a opinião dos empresários e as formas que estão trabalhando.

De acordo com Knechtel (2014), pesquisas quantitativas, são dados extraídos com o intuito mensurar quantidades numéricas e analisar o impacto primeiro com fontes primárias 
consequentemente depois com dados secundários já analisados e processados vindo a ter a resposta para aquele problema.

Segundo Michel (2009), pesquisas qualitativas são análises feitas através de opiniões, ideias que tenham coerência e que possa abranger aquela determinada pesquisa visto que não se comprova números estatisticamente. Creswell (2012) define como sendo técnicas qualitativas como as entrevistas abertas, fornecem informações sobre a própria interpretação assim oferecendo diversas perspectivas sobre o tema abordado.

A pesquisa foi realizada entre o período de 24/03/2020 a 15/05/2020, com uma amostra de 25 entrevistados. Tal amostra foi obtida através de uma estimativa das principais lojas de do setor varejista de materiais de construção do município, segundo a Associação Comercial e Empresarial de Guarapuava- ACIG-PR totalizando uma população de cerca de 50 lojas de materiais de construção. Para tanto considera se um nível de confiança de 95\% e uma margem de erro de $5 \%$.

A pesquisa é composta por sete questões sendo parte quantitativa e parte qualitativa aplicada no município de Guarapuava PR, com o intuito de abranger mais respostas e captar dados relevantes sobre como os empresários do setor varejista, estão sobrevivendo com suas empresas de materiais de construção com mediante a instabilidade gerada pela pandemia do COVID-19.

A coleta de dados ocorreu através de ligações, visitas aos estabelecimentos a e através das redes sociais como Whatsapp ${ }^{\circledR}$ e Facebook ${ }^{\circledR}$, visando a obtenção de informações e depoimentos dessa forma relacionando os impactos do COVID-19 através da ótica dos gestores das empresas.

\section{Apresentação e análise dos resultados}

Os dados obtidos através do questionário aplicado serviram de base para que fossem elaborados os gráficos para análise dessa forma, os dados obtidos por meio das pesquisas serão analisados e, assim, poderão gerar informações para demonstrar os impactos negativos sofrido nas empresas de materiais de construção. 
Para uma obtenção de dados mais detalhados, foi realizada questionário a respeito do comportamento e atitudes das empresas no período da pandemia do COVID-19, contemplando 25 respostas das empresas do segmento varejista de materiais de construção.

Os dados numéricos e opiniões expressadas a seguir, retratam o cenário, o ambiente e as possíveis estratégias que as empresas do setor estão fazendo utilizando e adequando-se.

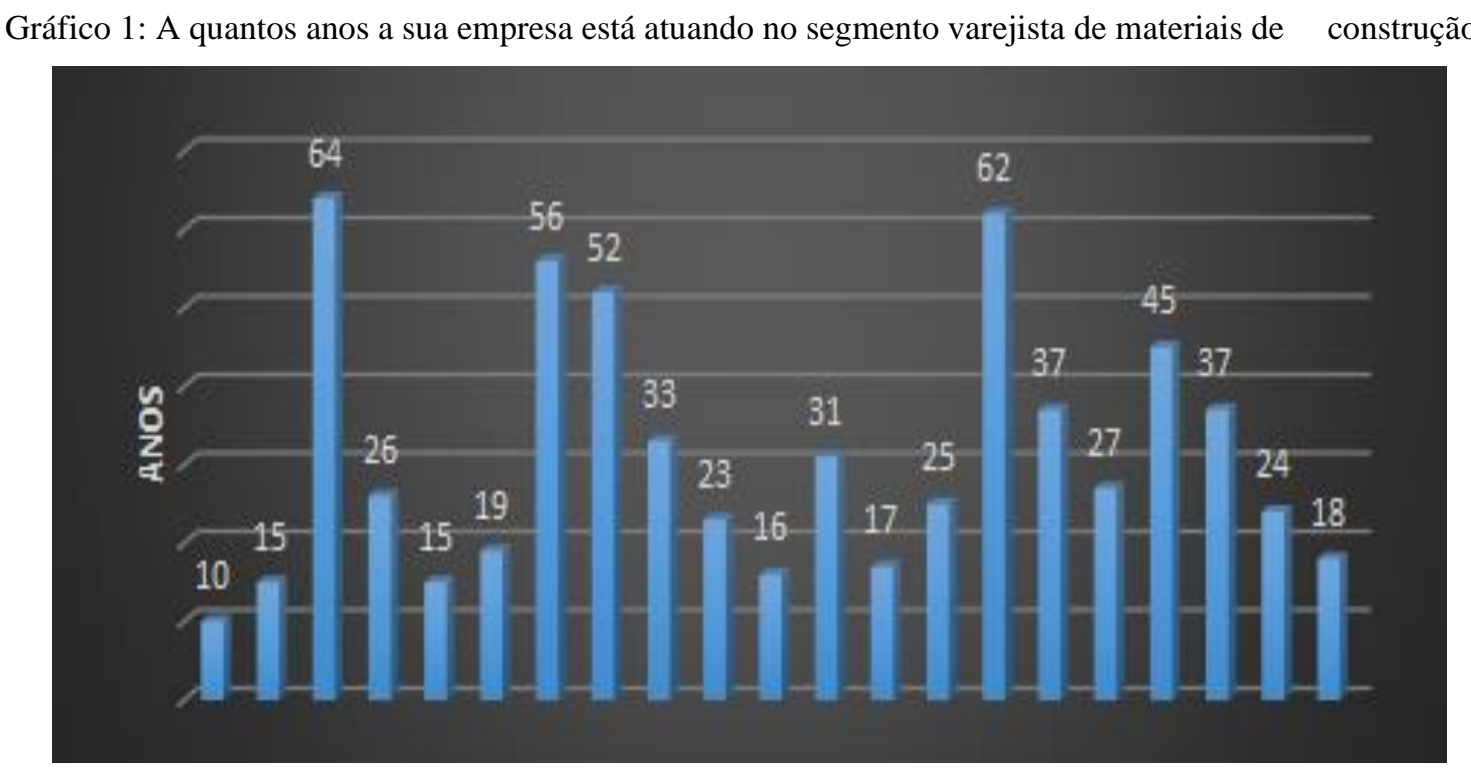

Fonte: Dados levantados pelos autores via sistema pesquisa de campo (2020)

O Gráfico 1 demonstra a quantos anos as empresas atuam no segmento varejista. Observa-se que as empresa estão atuando neste mercado a mais de 10 anos em Guarapuava - PR.

De acordo com a presente pesquisa, pode se observar que o fluxo de pessoas vem diminuindo devido ao distanciamento social e decretos já mencionados no presente artigo. Conforme demonstra o Gráfico 2. 
Gráfico 2: Com a pandemia do Coronavirus suas vendas diminuíram em uma escala de 1 a 5 ?

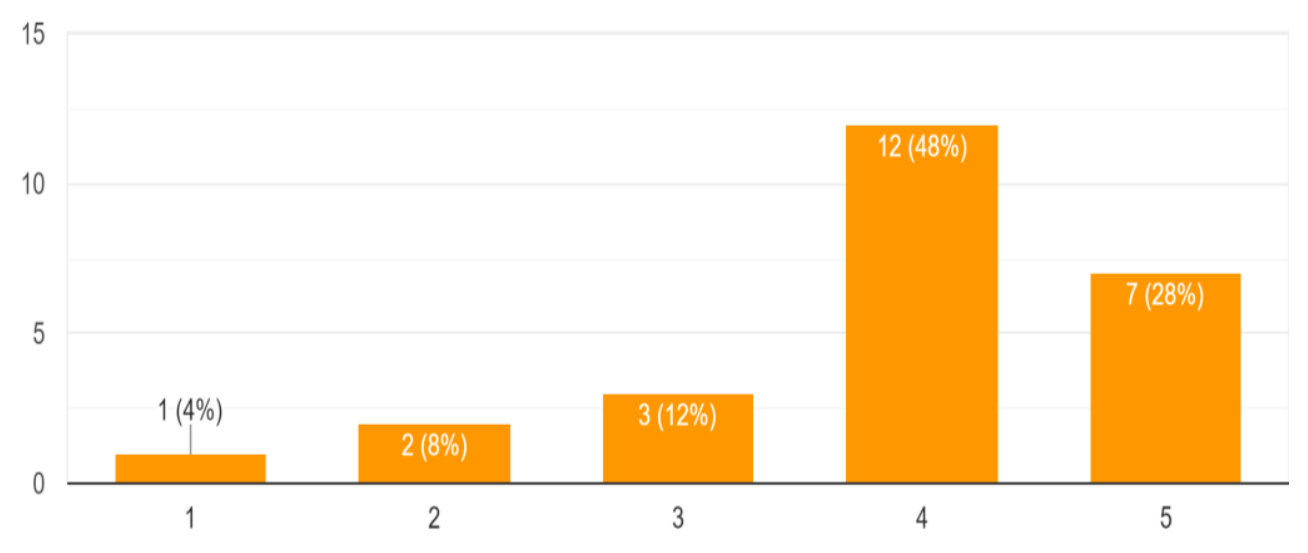

Fonte: Dados levantados pelos autores via sistema pesquisa de campo (2020)

Observa-se que com a pandemia ocorre uma grande diminuição nas vendas chegando a 48\% de perdas para setor na cidade.

Quando questionado sobre a importância do delivery, para as suas empresas os gestores enfatizaram a sua importância como é demonstrado no Gráfico 3.

Gráfico 3: Em uma escala de 1 a 5 qual a importância do delivery (entrega a domicílio) para sua empresa?

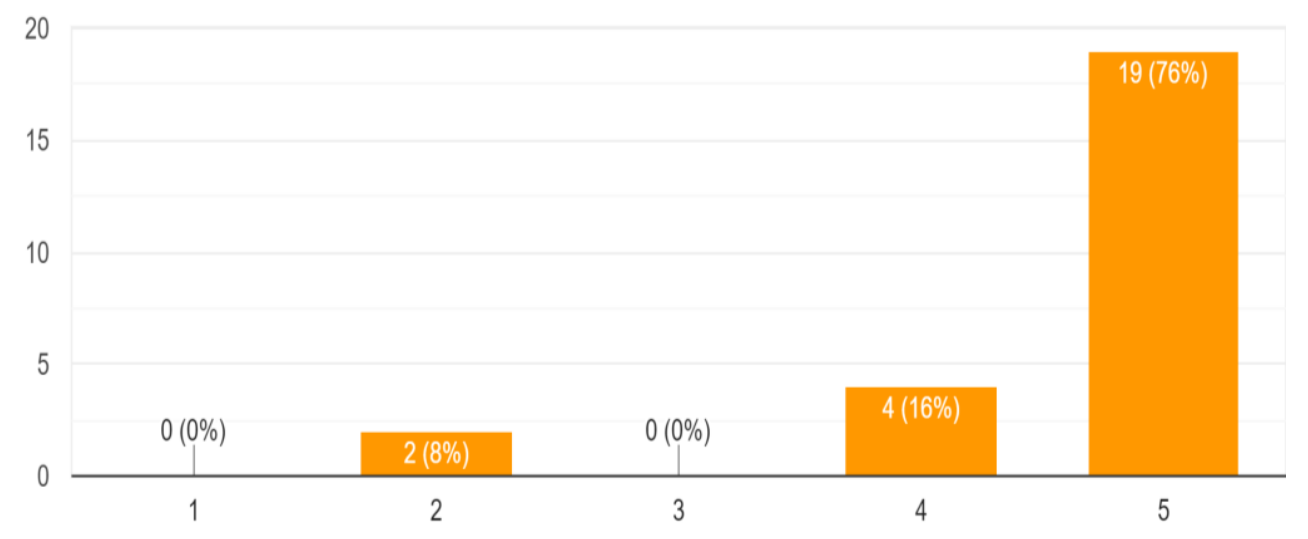

Fonte: Dados levantados pelos autores via sistema pesquisa de campo (2020).

Conforme demonstrado no Gráfico 3 o delivery é uma ferramenta fundamental para formar uma ponte entre a empresa e o cliente e é uma prática comum no setor, conforme dados de $76 \%$ das empresas entrevistadas. 
Os entrevistados apontam que aplicativos e redes sociais tem se tornado uma alternativa e uma ferramenta estratégica no relacionamento com os seus clientes como é apontado no Gráfico 4.

Gráfico 4: Quais dessas estratégias sua empresa está utilizando?

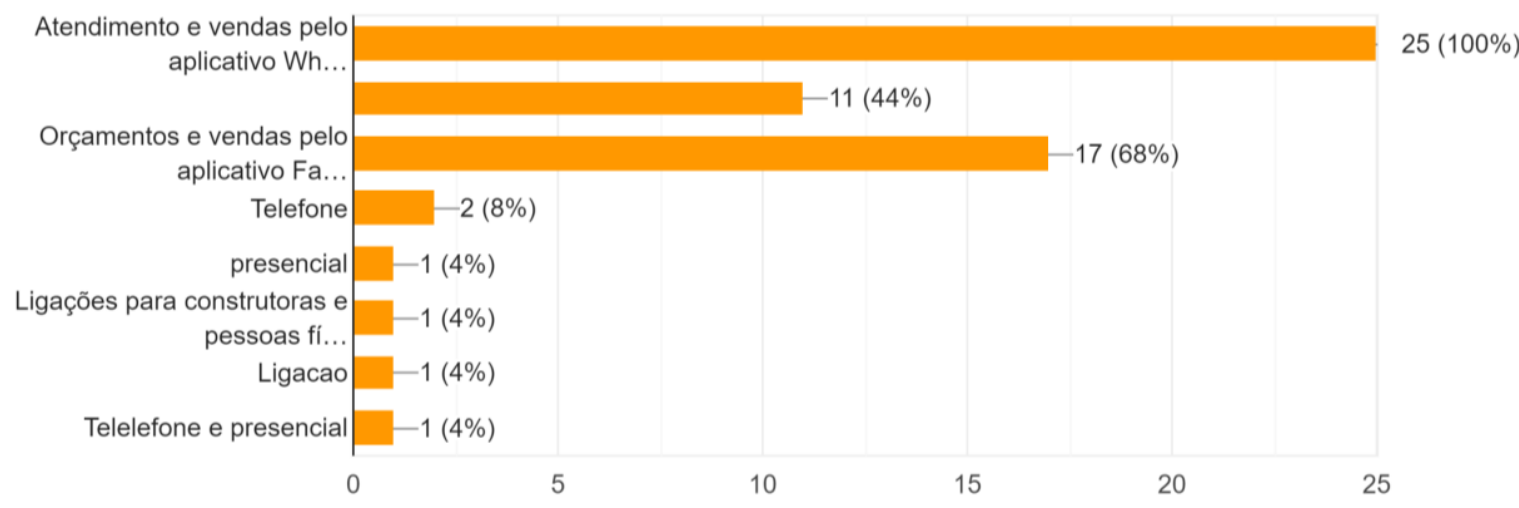

Fonte: Dados levantados pelos autores via sistema pesquisa de campo (2020)

De acordo com Gráfico 4, a maior parte das empresas estão adotando o atendimento via aplicativo WhatsApp ${ }^{\circledR}$, seguindo logo atrás com $68 \%$ o aplicativo Facebook®. Pois ambas são ferramentas que disseminam a informação sem a presença física. Vale salientar que os entrevistados escolheram mais de uma alternativa.

Em relação aos decretos municipais sobre os horários de funcionamento, os gestores das empresas apontam os impactos indiretos que ocasionaram ao setor em Guarapuava - PR, como é apresentado no Gráfico 5.

Gráfico 5: Como você classifica os impactos nos horários de funcionamento de seu estabelecimento em uma escala de 1 a 5 ?

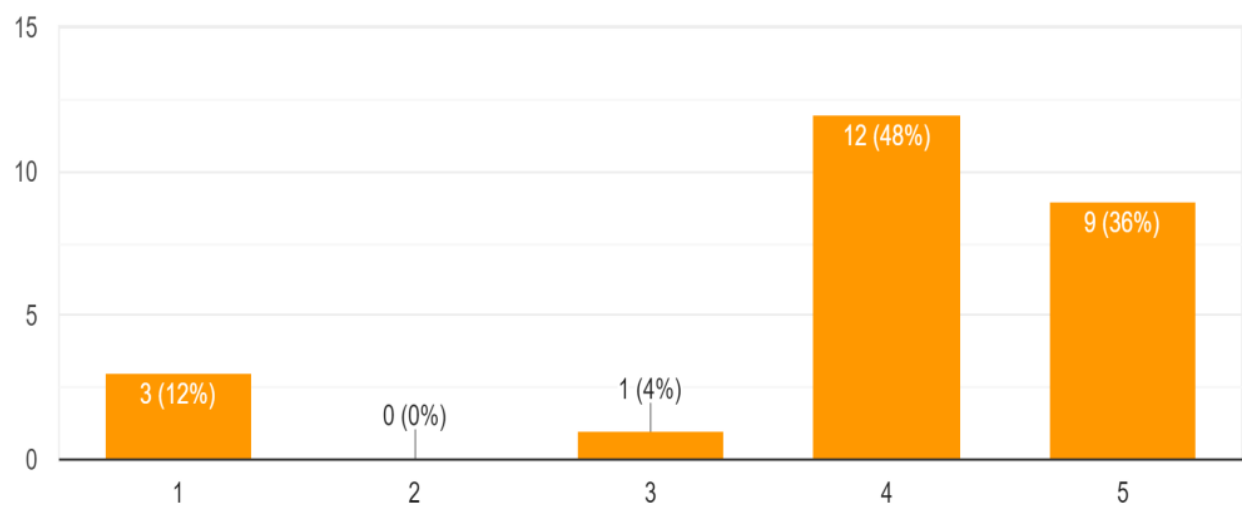

Fonte: Dados levantados pelos autores via sistema pesquisa de campo (2020) 
Conforme Gráfico 5, evidencia que $84 \%$ das empresas tiveram um impacto significativos no seu horário de funcionamento e consequentemente o fluxo de atendimento e vendas aos seus clientes.

Com um cenário em transformação, os entrevistados optaram por adotar redução na jornada de trabalho e consequentemente nos salários de seus colaboradores, dado esse explicitado no Gráfico 6.

Gráfico 6: Sobre o quadro de funcionários de funcionamento quais medidas foram adotadas?

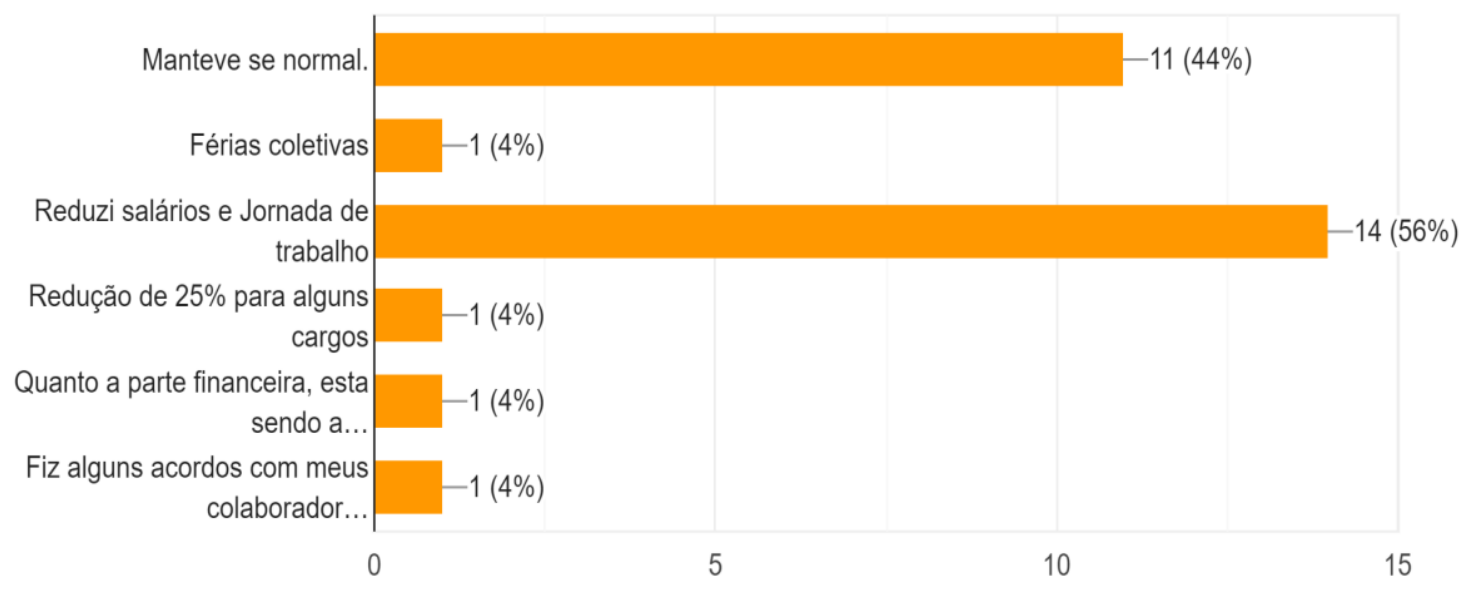

Fonte: Dados levantados pelos autores via sistema pesquisa de campo (2020)

A partir do estudo do gráfico 6 , pode se observar que com $56 \%$ a maioria das empresas para se manter no mercado optaram em reduzir a jornada de trabalho e consequentemente reduzir o valor salarial pago a seu funcionários.

Além das perguntas de múltiplas escolhas, a última questão era uma questão de opinião individual, onde os entrevistados poderiam deixar comentários, podendo ser críticas, sugestões e medidas a tomadas. Tais comentários são de grande importância. A Tabela 1 apresenta os comentários mais relevantes sobre a empresa analisada. 
Tabela 1: Pergunta de opinião individual da pesquisa.

O que sua empresa está fazendo para enfrentar essa situação da pandemia causada pelo novo Coronavírus?

“O momento é desafiador para nós empresários que estamos na linha de frente, estamos buscando alternativas para se manter buscando entender as necessidades de nossos clientes negociando prazos, formas de pagamento entre outras coisas que fique bom para ambos os lados."

"Seguindo as normas estabelecidas não perdendo as esperanças é só uma crise já passamos por outras e se mantivermos firmes."

"Fazendo tudo que está ao nosso alcance tomando as medidas preventivas e mantendo nosso efetivo normal, o que move uma empresa como o nosso grupo que é referência em matérias de construção são as pessoas que estão comprometidas com nosso trabalho e aos nossos clientes que confiam neste grupo."

"Estou reduzindo o máximo de gastos desnecessários, cortando despesas e negociando com meus fornecedores."

"Percebi um declínio nas vendas, por isso fiz uma reunião com meus colaboradores. Atendimento por telefone entregas gratuitas e promoções em algumas linhas de produtos."

"Estamos se adequando aos nossos clientes pois eles são nosso foco principal o que eu mais escuto aqui na loja é pedido de desconto, quando é possível negociamos por quantidade de compra dependendo a localização não cobramos frete."

"Estamos trabalhando conforme as exigências estabelecidas pelos decretos estabelecidos pela prefeitura de Guarapuava. Atendimento por telefone, estamos atendendo na loja física com número limitado de pessoas e também através de nosso site e Whatsapp."

Fonte: Dados levantados pelos autores via sistema pesquisa de campo (2020).

De acordo com a Tabela 1, os empresários estão se adaptando com suas empresas ao novo cenário de instabilidade. Alguns conseguiram se adequar de forma eficiente e inovadora, juntamente com seus funcionários e como muitos gestores enfatizam em seus comentários de estão passados por um momento desafiador e desenvolvendo estratégias em cenário de incertezas. 


\section{Conclusões}

Diante de um cenário econômico instável pode se concluir que as empresas buscam se adequar às normas, decretos e principalmente se reinventar neste período de grandes desafios. Com mercados incertos, clientes exigentes, diminuições na jornada de trabalho e quadro de funcionários para diminuir seus custos e para manter se competitivas em um ambiente de incertezas no setor varejista de materiais de construção, como se verificou no município de Guarapuava - PR

Vislumbrando uma melhora no cenário econômico as empresas estão estimulando cada vez mais os canais de comunicação não presencial, ou seja, usufruindo das redes sociais e aplicativos para a fomentação de produtos e prospecção de vendas dos mesmos.

Apesar da diminuição das vendas até o presente período da pandemia, surge a oportunidade de intensificação dos canais de distribuição e novos meios de comunicação com os clientes em potencial.

Adequando-se ao novo cenário, os empresários do setor buscam desenvolver estratégias que atendam as necessidades dos clientes em um contexto de instabilidade.

\section{REFERENCIAS}

ACIG. Com programa empresarial de prevenção, decreto estabelece novo horário para comércio. Disponivel em: <https://acig.com.br/com-programa-empresarial-de-prevencaodecreto-estabelece-novo-horario-para-comercio/> Acesso em: 25 de Abril de 2020.

CRESWELL, J.W. Qualitative Inquiry and Research Design:Choosing Among Five Approaches. Thousand Oaks, CA: Sage, 2012.

FERNANDES, Bruno Henrique Rocha; BERTON, Luiz Hamilton. Administração estratégica: da competência empreendedora à avaliação de desempenho. São Paulo: Saraiva, 2005. 264 p. ISBN 85-02-05114-8.

GIL, Antonio Carlos . Métodos e técnicas de pesquisa social. São Paulo, Atlas,2008.

KOTLER, Philip; ARMSTRONG,Gary. Princípio de marketing. 9.ed. Rio de Janeiro: Prentice Hall, 2003.

KOTLER, Philip; KELLER, Kevin Lane. Administração de marketing. 14. ed. São

Paulo: Pearson Education do Brasil, 2012. 
KNECHTEL, Maria do Rosário, Metodologia da pesquisa em educação: uma abordagem teórico-prática dialogada. Curitiba : Intersaberes ,2014.

LAS CASAS,A.L. Marketing: Conceitos, exercícios, casos.6.ed.São Paulo,Atlas,2011.

MICHEL, Maria Helena .Metodologia e pesquisa científica em ciências sociais .2 Ed.São Paulo: Atlas,2009.

GUARAPUAVA. Novo decreto reforça medidas de enfrentamento ao covid-19 em Guarapuava .Disponível em: <https://www.guarapuava.pr.gov.br/noticias/novo-decretoreforca-medidas-de-enfrentamento-ao-covid-19-em-guarapuava/> Acesso em: 15 de Abril de 2020.

POLIZEI, Eder. Plano de marketing. 2 ed. São Paulo: Cengage Learning, 2010. 146 p. Inclui bibliografia. ISBN 978-85-221-0890-9.

THIOLLENT, M. Metodologia da pesquisa-ação. São Paulo,2009.

UJVARI, Stefan Cunha. Pandemias: A humanidade em risco. São Paulo: Contexto, 2011. 220 p. ISBN: 978-8-7244-632-7. 